\title{
Differenz
}

Revista internacional de estudios heideggerianos y sus derivas contemporáneas

AÑO 7, NÚMERO 6: JULIO DE 2020. ISSN 2386-4877 - DOI: 10.12795/Differenz.2020.i06.03

[pp. 53-71]

Recibido: 01/06/2020

Aceptado: 18/06/2020

\section{La línea. Apuntes sobre el nihilismo en el intercambio epistolar entre Ernst Jünger y Martin Heidegger.}

\section{The line. Notes on nihilism in the epistolary exchange between Ernst Jünger and Martin Heidegger.}

Miguel Grijalba Uche

Universidad de Valladolid

Resumen:

En la primera mitad de los años cincuenta del siglo pasado se dio un intercambio epistolar entre Martin Heidegger y Ernst Jünger que fue el análisis más profundo del nihilismo como diagnóstico de nuestra época. Jünger plantea la superación del nihilismo mientras que Heidegger piensa que el nihilismo es el proceso por el que la verdad del Ser se ha ocultado, olvidando su esencia. Para poder superar el nihilismo debe antes ser comprendido en su esencia como acontecimiento que pertenece a la historia del Ser, en las aperturas epocales de la metafísica.

Palabras Clave: Línea; Superación del nihilismo; Técnica; Historia del Ser; Meridiano cero. 


\section{Abstract:}

In the fifties of the last century there was an epistolary exchange between Martin Heidegger and Ernst Jünger that was the most profound analysis of nihilism as a diagnosis of our time. Jünger proposes the overcoming of nihilism and Heidegger, thinks nihilism as the process by which the truth of Being has been hidden, forgetting its essence. In order to overcome nihilism, it must first be understood in its essence as an event that belongs to the history of Being, in the epochal openings of metaphysics.

Keywords: Line; Overcoming of nihilism; Technique; History of Being; Zero meridian.

\section{Introducción.}

En la primera mitad de los años cincuenta del siglo pasado se realizó un intercambio de textos entre Martin Heidegger y Ernst Jünger que resultó ser el análisis más profundo del nihilismo como diagnóstico de nuestra época. El nihilismo ha sido considerado como el mal constitutivo del siglo precedente en donde se dio una crisis de valores tradicionales procedentes del cristianismo, de la llustración y del racionalismo, y que se caracterizó por el surgimiento de los totalitarismos, de las guerras mundiales y del fracaso de una concepción mecanicista y positivista del mundo tecno-científico.

El texto titulado Sobre la línea (1950) Jünger lo escribió para el sexagésimo cumpleaños de Heidegger y en él centra la atención sobre el problema del nihilismo y la necesidad de su superación. Heidegger reconoce la visión pedagógica de Jünger sobre la realidad actual con sus dos rasgos: la técnica y el nihilismo¹. Fue respondido el texto por Heidegger con ocasión de idéntico cumpleaños de Jünger (1955) mediante otra carta con una visión más profunda, más racionalista y más académica. Para Heidegger, Ernst Jünger fue el único que pudo ir más allá de Nietzsche al pensar el nihilismo como un "destino de la historia de Occidente".

Como casi todos sus contemporáneos, Jünger usó el término nihilismo como adjetivo más que como sustantivo, pero rara vez se detuvo a definir qué es el nihilismo. Esto se debe a que su preocupación era mucho más la superación del nihilismo que su acotación, ya que se podía prescindir de definir algo que era una realidad conocida por todos, en tanto que ya se había vivido el final y hundimiento del liberalismo ilustrado decimonónico y del cosmopolitismo de la República de Weimar.

1 VoLPI, F. El nihilismo. Madrid, Siruela, 2012, p.124. 
El presente trabajo analiza estos dos textos sobre el nihilismo siendo lo que los distingue la forma cómo expresan sus conclusiones antagónicas. La reconstrucción del debate entre los dos autores, en parte reducido al intercambio epistolar, se completa con el volumen 90 de las obras completas de Heidegger titulado Zu Ernst Jünger, donde han sido recopiladas las anotaciones heideggerianas de los años treinta sobre los escritos globales de Jünger.

\section{2. ¿Qué queremos decir con nihilismo? Un acercamiento desde ambos autores.}

Para Jünger, el nihilismo es un término confuso y polémico que es empleado como epíteto descalificativo, pero del que no podemos sustraernos como destino. Por ello se propone limpiar de malezas el camino de falsas interpretaciones que intelectuales posteriores a Nietzsche desarrollaron en sus trabajos. A pesar de su participación en ambas guerras mundiales, la actitud de Jünger es optimista cuando huye del nihilismo extremo. Y se debe, en su consideración, porque el nihilismo no es una fatalidad ni un final, sino un proceso que puede ser superado, "recubierto de una nueva piel, como una cicatriz" ${ }^{\text {. Por }}$ lo tanto, la necesidad de una buena definición viene de que sería como el "descubrimiento del agente cancerígeno. No significaría la curación, pero sí su condición"3. Heidegger no comparte esa perspectiva de curación ${ }^{4}$. En un momento dado, haciendo referencia a la exigencia por parte de Jünger de alcanzar una buena definición del nihilismo afirma Heidegger: "La bondad de la 'buena definición' exigida con todo derecho, encuentra su acreditación en que abandonemos el querer definir"s.

Jünger, desde su herencia nietzscheana (a quien lo define como el primer y último nihilista de Europa) considera al nihilismo como una fase de un proceso espiritual que se sustenta en la devaluación de todos los valores supremos, fundamentalmente cristianos ${ }^{6}$. Sin sentido ni unidad ni esperanza, los conceptos tradicionales (Dios, Bien, Verdad) pierden su valor al desmoronarse el antiguo orden y transformarse el mundo ${ }^{7}$. No hay absolutos, ni obra de arte total ni verdad superior, incluso en la moral hay una cierta provisionalidad y el vacío interior reinante provoca en los individuos la necesidad de

2 JüngeR, E.; HeIDEgGer, M. Acerca del nihilismo. Barcelona, Paidós, 2010, p. 16

3 lb. p. 26.

4 lb. p. 76.

$5 \mathrm{lb}$. p. 107.

6 lb. p. 16.

7 VolPI, F. Op. cit., pp. 164-165. 
nuevas normas que les eximan de la responsabilidad de su destino ${ }^{8}$. La consecuencia será la confusión en el hombre y la proliferación de filosofías que intentan orientarlo hacia caminos alternativos mediante nuevos valores orientadores o prácticas coercitivas que no encuentran resistencia en la religión ni en la ética. El nihilismo se convierte en problema central para nuestra época porque supone la consunción de lo antiguo sin que se vea surgir el meridiano cero, la salida que nos anuncia Jünger ${ }^{9}$ e infunde pánico en el hombre al hacer crecer en él una debilidad por los rumores nihilistas que, a su vez, le pueden llevar a sucumbir por la presión ${ }^{10}$.

El nihilismo es un proceso histórico-mundial que, en la perspectiva de Jünger, tiene una connotación especialmente política y cultural, por eso no es extraño que cite a Nietzsche y a Dostoievski. Tanto Nietzsche como Dostoievski ven una misma realidad y los dos tienen una misma evolución que progresa desde la duda al pesimismo de un mundo sin valores ${ }^{11}$. Frente a la visión espiritual de Nietzsche, Dostoievski es más optimista (como Jünger) en cuanto que el nihilismo no es una fase final y se puede solucionar. Si el nihilismo se muestra en el aislamiento singular de Raskolnikov que publicó en 1886 en El Mensajero ruso, o en el estudiante Hipólito de El idiota, se trata de un nihilismo activo que supone un incremento de poder ${ }^{12}$. Tal vez la única diferencia es que, mientras para el escritor ruso, el nihilismo es curable a través del dolor (reconocimiento público de la culpa), en Nietzsche, el nihilismo es la expresión de la decadencia.

Este proceso de devaluación de los valores supremos ha alcanzado, de algún modo, caracteres de perfección en la actualidad de modo que hay que entenderlo en la acepción de Heidegger, compartida por Jünger, como aquella situación en que este movimiento se encuentra presente en todas partes ${ }^{13}$. Para Jünger el problema es cómo preparar al hombre, obligado por su autoconservación, a comportarse en un mundo donde el nihilismo se ha convertido en ese estado normal ${ }^{14}$. La dificultad de esta preparación radicará en que es imposible una representación de la Nada en el espíritu del hombre, una aniquilación repentina ${ }^{15}$. Pero conocer la época es experimentar en sí el poder de la Nada,

8 JÜNGER, E.; HEIDEGGER, M. Op. cit., p. 24.

9 VOLPI, F. Op. cit., p. 119.

10 JÜNGER, E.; HEIDEGGER, M. Op. cit., pp. 21-22.

11 lb. p. 25.

12 Hervier, J. Conversaciones con Ernst Jünger. México D. F., Fondo de Cultura Económica, 1990, p. 73.

13 JÜNGER, E.; HeIDEGGER, M. Op. cit., p. 38.

14 lb. p. 49.

15 Ib. p. 25. HeIDEgGer, M. ¿Qué es Metafísica? Madrid, Alianza Editorial, 2018, p. 31. 
nos dirá contrariamente Heidegger ${ }^{16}$, porque la Nada domina el nihilismo y la esencia humana pertenece a la esencia del nihilismo en nuestro tiempo ${ }^{17}$. Hay que experimentar el poder de la Nada para que el despliegue total del nihilismo lleve a su agotamiento, nos concluye Heidegger ${ }^{18}$. Con lo cual, surge el problema de cuál será la actitud adecuada del hombre ante la situación nihilista, si puede llegar al punto cero de Jünger o hacia una nueva donación del Ser, en palabras de Heidegger ${ }^{19}$.

Jünger excluye tres interpretaciones a las que él mismo no había estado tan lejos de suscribir, por lo que este pasaje puede considerarse una parcial autocrítica. El nihilismo descarta lo caótico, lo enfermo y lo malo. El nihilismo no es el caos aunque existe la idea de un orden que se pierde. Jünger estuvo muy cerca de creer que, si el caos no era la esencia del nihilismo, al menos parecía ser una de sus consecuencias más visibles porque la edad burguesa que rechazó es una edad sin figura. Pero se refería especialmente al caos político cuya imposibilidad de resolución se le achacaba al parlamentarismo de la república de Weimar ${ }^{20}$. Del mismo modo, también rechaza la enfermedad. Ya Nietzsche había considerado al nihilismo como una suerte de enfermedad cultural y negación de la vida. Jünger tiene también a la vista precisamente la experiencia histórica que intentó superar el nihilismo acudiendo a una eugenesia racial que tenía como fin eliminar los supuestos enfermos y degenerados. Pero antes que nada, Jünger está pensando en los estados de bienestar, especialmente el estadounidense, a los cuales considera nihilistas constatando así que la salud física en realidad está unida al nihilismo ${ }^{21}$. Y, en tercer lugar, el nihilista no es un criminal en el sentido tradicional, pues para ello tendría que existir todavía un orden, si bien el mal se puede aprovechar de la situación nihilista ${ }^{22}$. Jünger está comprendiendo la concepción del mal como una privación, más bien, entre el derecho y la injusticia. En este punto se repite la idea de que el nihilismo no destruye lo existente, sino que simplemente le priva de substancia, le quita el éthos, hace que las cosas sigan marchando sin tradición. Si bien es cierto que Jünger había calificado el nihilismo como "la fuente más honda del mal", no creo que se pueda decir que la interpretación del nihilismo que está rechazando sea ejemplo de su pensamiento, puesto que Jünger no calificaba al nihilismo a partir de valoraciones como bondad o maldad.

16 JÜNGER, E.; HEIDEGGER, M. Op. cit., p. 79.

17 Ib. p. 109.

18 VolPI, F. Op. cit., p. 130.

19 JÜNGER, E.; HEIDEGGER, M. Op. cit., p. 90.

20 lb. p. 28. Cfr. CUASNicú, R.F. Jünger y lo político. Buenos Aires, Prometeo, 2014.

21 lb. p. 31.

$22 \mathrm{lb}$. p. 38. 
En los comentarios de Heidegger, Ernst Jünger da una descripción limitada del nihilismo al faltar una topología que unifique Ser y Nada en su esencia, necesaria para que permita una superación del problema ${ }^{23}$. Según Heidegger, el nihilismo es el proceso por el que la verdad del Ser, su esencia, se ha ocultado, llevando a pensar lo ente desde lo ente. El nihilismo supone, por tanto, el abandono del hombre en mitad de lo ente. Este hecho se ha mantenido durante más de dos mil años y no somos aún conscientes de la mayor negación, el vacío y la nada. Sólo el ente tiene preeminencia en la época actual donde se consume la metafísica y su esencia se materializa en la técnica ${ }^{24}$.

En este sentido Ernst Jünger nos dirá que la nueva huída nihilista se desarrolla en el espíritu actual de un desarrollo económico y de una tecnología que suministran un estímulo para el aburrimiento rutinario de la existencia. Así, en el interior del nihilismo de la aniquilación, de la devastación ética, familiar, política, estética se crea un ser humano con una interioridad cada vez más lábil, sugestionable, cobarde que Jünger denomina reducción ${ }^{25}$. Este último hombre es el que ha inventado la seguridad y el confort ${ }^{26}$. El desarraigo existencial, generado por la carencia de fundamento y la fuerza de lo científico y técnico, persiste a costa del ocultamiento del Ser ${ }^{27}$. Este movimiento nihilista puede girar hacia una Nada aniquiladora o hacia una nueva donación del Ser, que Heidegger lo expresa tachándolo, para expresar el origen y la consumación del nihilismo. La Nada, que en un primer momento servía como plataforma para tomar distancia del ente y abrirse a la diferencia ontológica, se convierte ahora en la otra cara de un ser formal, vacío, que anula toda responsabilidad y crítica ${ }^{28}$.

Partiendo de la fenomenología del nihilismo de Jünger, Heidegger quiere profundizar en el tema central y afirma que, para cruzar la línea, para poder superar el nihilismo como dice Jünger, debe antes ser comprendido en su esencia como acontecimiento que pertenece a la historia del Ser, un donarse y un sustraerse, en las aperturas epocales de la metafísica. Hay que pensar en una topología del nihilismo que le faltó a Jünger y caracterizar a la historia del Ser como el lugar esencial en el que se decide el destino del nihilismo.

\section{3 lb. pp. 109-112.}

24 SÁnCHeZ-MeCA, D. El nihilismo. Madrid, Síntesis, 2010, p. 162.

25 JÜNGER, E.; HEIDEGGER, M. Op. cit., p. 122.

26 Ib. p.54. Cfr. JüngER, E. Tratado del rebelde. Buenos Aires, Sur, 1963.

27 EstradA, J.A. "La crisis axiológica y el nihilismo de Heidegger". Pensamiento, 74, 2018, p. 558.

28 Ib. p. 564. Cfr. DA SA, A. A política sobre la linhea: Martin Heidegger, Ernst Jünger e a confrontacao sobre a era do niilismo. Covilha, Luso Sofia Press, 2008. 
En los años treinta, Jünger expresó varias veces su convencimiento de que la Gran Guerra puso fin a la era del sentimentalismo burgués que había llevado de la revolución industrial del siglo XIX al despliegue destructivo de las guerras mundiales y de la revolución rusa como nuevo rostro de la voluntad de poder en una época marcada por la técnica. Este corte abrupto con la época burguesa señala el comienzo de la edad del Trabajador definida por ser una inversión de las viejas valoraciones ${ }^{29}$. Jünger presenta la crisis de la civilización como el tránsito a esta nueva situación en donde el trabajo, organizado por la técnica como forma de realidad, moviliza todos los recursos planetarios en el seno del nihilismo.

Heidegger acusa a Nietzsche de ser el último metafísico que ha anunciado la muerte de Dios para sustituirlo por el hombre, como dador de sentido ${ }^{30}$. Ha muerto Dios y su lugar lo ocupan la voluntad de poder del sujeto que funda y valora los ídolos que pertenecen a lo ente incluyendo lo suprasensible, las metafísicas de fundamento, las verdades supranaturales, etc. Con la filosofía de Nietzsche la metafísica llega a su consumación, es decir, a trascender el nihilismo de debilidad del espíritu, la constatación de la nada carencial que nos afecta y en la que él mismo se ha convertido en esclavo de lo ente que piensa en lo ente con un pensar representativo ${ }^{31}$.

\section{La máscara del nihilismo.}

Jünger reconoce la máscara que oculta al nihilismo en los totalitarismos políticos y en la tecnología que le llevan a sospechar que todavía no se ha alcanzado el nihilismo completo que Nietzsche anunciaba. Nihilismo y poder son inseparables. Durante el siglo XIX la ciencia y la técnica fueron vistas como humanizadoras por ser desarrollos de la razón, pero a inicios del siglo XX no tuvimos un referente antropológico y ético que nos permitiese decidir ante las posibilidades que nos abría la técnica. La técnica es capaz de someter todo a su disciplina, dice Jünger, al arrancar al ser humano su libertad singular poniéndose al servicio de los poderes políticos y económicos, el Leviatán ${ }^{32}$. Las condiciones de existencia y los principios teóricos y de sentido de épocas pasadas ya han dado todo de sí.

El despliegue tecnocientifico se ve legitimado por el aumento de producción de capital y el incremento de la calidad de vida. Este progreso tecnológico produce un retraso

29 Ib. p.55. Interesante en este punto la lectura del texto de Jünger El Trabajador. Dominio y figura (Barcelona, Tusquets, 1990).

30 Estrada, J. A. Op. cit. p. 557.

31 lb. p. 556.

32 Cfr. PorCEL, D. "El lugar de la libertad en las sociedades nihilistas", en Brocar 33, 2009, 263-283. 
espiritual que somete al hombre a una nueva época con carencia de valores, criterios pragmáticos y tecnocráticos, evasión, ocio consumista, masificación urbana. Lo que se consigue es la progresiva deshumanización por el sometimiento a la técnica cuyos objetivos coinciden con el nihilismo: anular toda existencia posible que no contribuya a acrecentar su poder. Pero el Jünger optimista cree que el espíritu no desaparecerá en la transición a la nueva época ${ }^{33}$.

Por primera vez se hace espacio a la idea de que la técnica es un factor de nihilismo: cuando a la nueva forma no corresponde el desarrollo de contenidos adecuados, cuando la realidad es transformada y plasmada por la técnica sin que las ideas, las personas y las instituciones se adecuen con la misma rapidez, cuando la disciplina, la capacidad de organización, el potencial energético crecen sin un igual crecimiento de nueva sustancia, entonces la técnica produce nihilismo ${ }^{34}$.

La técnica en sentido jüngeriano es esencialmente el modo como la forma del Trabajador moviliza el mundo actual para destruir el viejo, el del individualismo burgués, el de la iglesia y el de la democracia libera| ${ }^{35}$. El hombre deja de ser humano, en el sentido humanista y antropocéntrico del término, y se mecaniza prescindiendo de su personalidad individual. La técnica contribuye a este dominio del hombre y del mundo, al mismo tiempo el hombre le entrega su alma a la técnica.

El Trabajador no concibe la técnica como un medio del bienestar sino que se sirve de ella para su conocimiento y se configura como el mayor despliegue de la subjetividad moderna frente a la totalidad del ente, con fines de dominio y explotación a escala planetaria, gracias a dispositivos técnicos cada vez más perfeccionados. Representa, por lo tanto, la voluntad de ser más fuerte para reducir el mundo a puro correlato objetivo de su propia posición ${ }^{36}$. El Trabajador es una nueva y especial voluntad de poder, una manera de aparecer el ser del ente, en palabras de Heidegger ${ }^{37}$. En El Trabajador y en La movilización total Jünger desarrolla un diagnóstico de la voluntad de poder en la época tecnológica sin ser una demonización de la técnica, ni un elogio sino una impresión de una realidad: la nueva figura del Trabajador se medirá por la posibilidad de producir la mayor

33 HeRVIER J. Op.cit., p.107.

34 VoLPI, F. Op. cit., pp. 108-109.

35 JÜNGER, E.; HEIDEGGER, M. Op. cit., pp. 147 y ss. Cfr. RoldÁN, D. P. "Tecnoanthropos o el trabajadorsoldado. Guerra, técnica y domesticación humana en la obra de Ernst Jünger (1920-1933)", en Revista de Filosofia 18 (22), 2006, pp. 111-146.

36 lb. p. 94.

37 Ib. p. 90. Cfr. JüNGER, E. Sobre el dolor. Barcelona, Tusquets, 1995. 
movilización de fuerzas, la movilización total, que será personificada por el Estado, el Leviatán, que puede aplicar el dominio técnico a las prácticas con métodos de destrucción masiva más contundentes. Heidegger dirá en otra ocasión hablando sobre El Trabajador y Sobre el dolor que ambas hablan el lenguaje de nuestro tiempo ${ }^{38}$. Según esto, el lenguaje de la descripción es entregado al representar desde las experiencias fundamentales del ente en su totalidad, esto es, desde el dominio total propio del final de la metafísica de Occidente, desde la técnica ${ }^{39}$. En la tecnificación tiene lugar una muerte de la metafísica, que es la interpretación que hace Heidegger. La Gestell de Heidegger coloca, ordena, distribuye y hace disponible el dominio mundializado, la técnica que le es entregada al hombre. Ahora es el momento de la verdad del ente en la figura de la producción y del consumo ilimitado, de la racionalización, de la calculabilidad, de la maquinación y de la automatización tecnológica de la vida mediante el mecanicismo y la matematización ${ }^{40}$. De este modo, el pensar se deprecia por el tiempo de cálculo, hallazgo técnico y éxito económico ${ }^{41}$.

Señala Jünger, en El Trabajador, que la esencia humana es fuente de dotación de sentido y otorga al hombre una nueva voluntad de poder cuyo propósito radica en el apoderamiento de sí mismo. Por tanto, el Trabajador no representa ni un estamento, ni una clase, ni una nación. No es una magnitud económica sino un carácter planetario. Su meta es lograr la totalidad en la figura del Trabajador por medio de la movilización del espacio técnico. Pero, sin embargo, Heidegger considera que el Trabajador y el eidós platónico pensados en su procedencia tienen un origen común en la época técnicometafísica de la Gestell. Según Heidegger, el Trabajador como voluntad de poder establece un platonismo invertido que concluye el ciclo de la metafísica. Esta inversión se muestra en la conformidad del Trabajador como figura con el eidos ( $\varepsilon \iota \delta \circ \varsigma$ ) platónico (es decir, “aspecto", “forma”, "figura", “tipo", “especie”) ${ }^{42}$. La subjetividad del Trabajador y del trabajo que realiza, que se fundan sobre las posibilidades abiertas por la instrumentalidad técnica, pretende la dominación del caos e introduce el sentido del Ser como la propia voluntad de poder.

La técnica es la figura de la época en la cual el Ser se manifiesta y, a la vez, se oculta al cumplimiento del destino metafísico de Occidente $^{43}$. La esencia de la técnica es el

$38 \mathrm{lb}$. p. 82.

$39 \mathrm{lb}$. p. 79.

40 SÁNCHEZ-MECA, D. Op. cit., p. 181.

41 JÜNGER, E.; HeIDEgGER, M. Op. cit., p. 101.

42 lb. p. 97.

43 VoLPI, F. Op. cit., p. 127. 
proyecto metafísico que abarca a todos los ámbitos de la realidad: pérdida de distancia por implementación de los medios de trasporte; destrucción de recursos materiales para el consumo; incremento de información sin control; espectáculo de la guerra; globalización de los modos de vida y uniformización del mundo; política subordinada a la economía mundial, etc. Esta voluntad de la técnica significa producción absoluta de la totalidad del ente, fabricar por fabricar, explotación de la tierra hasta el agotamiento, acumulación de bienes, fabricación de armamento. Y se debe a que la técnica obedece a su propia lógica interna: planificación de todos los dominios del ente regulados por intervencionismo estatal; usura encaminada a satisfacer las necesidades humanas; y la uniformidad con la desaparición de jerarquías y las diferencias de opiniones, gustos, tendencias ${ }^{44}$.

El hombre se ha convertido en funcionario de la técnica y no es el compañero del Ser sin capacidad de responder a su llamada, nos afirma Heidegger. El hombre es seducido por el confort, el bienestar, la satisfacción, y se extiende por todo el planeta una indiferencia hacia la pregunta por el Ser ${ }^{45}$. El Trabajador de Jünger que afirma la realidad de una nueva humanidad y la nueva época de los titanes (hombres capaces de dominar la maquinaria de la técnica) es también, según Heidegger, una forma de nihilismo activo. La llamada del Ser al hombre sólo vendrá, para el pensador de Messkirch, desde la técnica que deje ver la pertenencia del hombre al Ser en el Ereignis como origen de una curación por la constatación de esa copertenencia ${ }^{46}$. La duda es si este Ereignis será capaz de dar lugar a una nueva época y será el acontecimiento por el cual seremos reapropiados al Ser y desapropiados a la metafísica.

La explotación es lo propio del mundo de la máquina, el estado monstruo, el Leviatán ${ }^{47}$. Cuando culmina el nihilismo se presentan dos miedos: el espanto ante el vacío interior por la pérdida de valores y el ataque del mundo automatizado. En esto reside el poder del Leviatán de nuestro tiempo ${ }^{48}$. Según lo expresado por Jünger en Sobre la línea, es la disputa con el Leviatán (ente que representa las fuerzas y procesos de la época) la más amplia en este mundo y le dedica una especial mirada a la liberación del miedo ante un Leviatán supuestamente invencible. Se trata de no temer la amenaza permanente y no caer en un escepticismo ${ }^{49}$. La organización de cientos de miles de seres libres de miedo

44 SÁNCHEZ-MECA, D. Op. cit., pp. 186-187.

$45 \mathrm{lb}$. p. 188.

46 JÜNGER, E.; HEIDEGGER, M. Op. cit., p. 101.

47 Ib. p. 56.

48 lb. p. 57.

49 "Los dominadores viven con el terror de que se liberen del miedo no unos pocos sino muchos", lb. p. 62. 
cambiaría una situación colectiva frente al miedo por el silencio de sociedades gobernadas por el objetivo del confort. El Leviatán ama las ideologías quietistas y desea adoración. Por ello, los tiranos imponen el miedo, se persigue el pensamiento y la creación.

Jünger hace una llamada a la responsabilidad para realizar la tarea de nuestro ser en el mundo a través de nuestra naturaleza interior que se base en la libertad del hombre para seguir o no las demandas de su ser. Los poderes que proceden del Estado totalitario de las sociedades tecnocráticas carecen de fuerza para impedir al individuo lo que su naturaleza propia le permite hacer. Habrá un reducto, el bosque que denomina Jünger, donde es inaccesible al Leviatán y desde el que resistir por la decisión personal para ser actualizados. Allí la persona singular puede recluirse y sobreponerse al automatismo técnico por el acceso a su naturaleza interior. El hombre puede vivir de modo distinto lo que le imponen las circunstancias de los imperativos políticos y tecnológicos, en realizar modos de vida que no se ajustan al estilo de las sociedades capitalistas de bienestar y consumo. La libertad no habita en el vacío, mora en estos lugares que denomina "tierra salvaje", lugar en el cual el hombre no sólo debe esperar luchar, sino también vencer ${ }^{50}$.

En conclusión, no sabemos si nos quedamos en esta época estabilizados con su despliegue en la Gestell o bien damos un salto abrupto hacia lo que no ha tenido lugar y no sabemos si va a ocurrir. Pero lo que no parece previsible es que vaya a cambiar esta época de la técnica, seguridad y satisfacción. Entonces, ¿̇hacia dónde nos dirigimos?

\section{4. ¿Hacia dónde va el nihilismo?}

En el $§ 11$ del texto de Jünger se dice que el nihilismo es un proceso de reducción, la desaparición de todo romanticismo, el modo como se traduce la concepción nietzscheana de la desvalorización de todos los valores hacia el punto cero, y, sin dudas, es este proceso el que se anticipaba como simplificación, pérdida del éthos y de la tradición al que nos referíamos previamente ${ }^{51}$. Una reducción a todos los niveles material o espiritual, económica o sanitaria, política o estética que será percibida como referencia del mundo con su pluralidad a un denominador más sencillo ${ }^{52}$, como desaparición del asombro y veneración de lo maravilloso que nos lleva hacia un vértigo frente al abismo cósmico con el cual expresa ese miedo a la $\mathrm{Nada}^{53}$ o como la creciente inclinación a la especialización que llega a niveles tan altos que "la persona singular sólo difunde una idea ramificada, sólo

50 lb. p. 62.

$51 \mathrm{lb}$. p. 43.

$52 \mathrm{lb}$. pp. 39-40.

$53 \mathrm{lb}$. p. 41. 
mueve un dedo en la cadena de montaje". Bajo esta situación se produce el surgimiento de religiones sustitutorias (ciencias naturales, apóstoles o partidos políticos) ${ }^{54}$ o también, desde el punto de vista negativo, la reducción nos remite a la mensurabilidad, a la consideración económica del mundo histórico y social llegándose a la confusión del valor por el precio ${ }^{55}$ para purificarse a través del dolor en referencia a Nietzsche y Dostoievski ${ }^{56}$.

La reducción que avanza en la edad del nihilismo tiende hacia su punto absoluto, en el cual todo queda reducido a Nada. Por ello Jünger ve en el proceso del nihilismo un paso necesario para que la humanidad pueda alcanzar "un nivel superior al que había antes de la entrada en el nihilismo"57. El pensamiento de Jünger es un pensamiento del cruce de la línea para salir del nihilismo más que un pensamiento en la línea que determina la zona del nihilismo y cobija en su esencia ${ }^{58}$. A un lado de la línea está la reducción y más allá la ganancia, nos dice Jünger. Pasar la línea es la exigencia que la época impone al hombre contemporáneo. Lo característico de la posición de Jünger no es sólo que hay una frontera entre una edad nihilista y otra edad ya no nihilista, sino que en realidad ya la hemos cruzado, o al menos hemos dado los primeros pasos. Él tiene del cruce de la línea la imagen de una serpiente, de la cual, "[I] cabeza está más allá de la línea"59, y que el resto del cuerpo la seguirá pronto. Esto explica el optimismo acerca de la "nueva donación del Ser" al pasar la línea.

Para Heidegger esta línea debe ser una frontera entre un nihilismo que sucumbe en la Nada o una nueva donación del Ser, una ambigüedad que nos genera incertidumbre ${ }^{60}$. El hombre no está ni más acá ni más allá de la línea del nihilismo sino que está implicado en su esencia. Heidegger nos comenta que el punto o meridiano cero de Jünger es la línea y la consumación, la Nada. ¿Cuándo se produce la consumación? Cuando el nihilismo está por todas partes y se ha convertido en estado normal y se da la concentración de todas las posibilidades esenciales del nihilismo ${ }^{61}$. Pero necesitamos conocer la esencia del nihilismo, sus potencialidades, esto es, el pensar. Los malentendidos vienen de la aversión del pensar, nos dice Heidegger. Y la esencia del nihilismo afecta a la dignidad de

54 lb. p. 42.

55 lb. p. 44.

56 lb. p. 46.

57 lb. p. 45.

58 lb. p. 75.

59 lb. p. 50.

60 lb. p. 54.

61 lb. p. 84. 
ese pensar ${ }^{62}$. La conclusión a la que llega Heidegger es que la última fase ha llegado a su término y se puede expresar por una línea. El nihilismo, a diferencia de Jünger, no tiene curación ${ }^{63}$.

Jünger pretende un juicio de la situación, nos dice Heidegger ${ }^{64}$, pero ésta precisa una determinación de la esencia del nihilismo. Al faltar este saber, hace superficial el juicio del primero, ya que el conocimiento de cómo salvarnos es limitado. No hay respuestas seguras más que en los charlatanes o ignorantes. No conocemos las causas de nuestra situación ni los medios de salvación ${ }^{65}$. La pregunta que surge entonces es cómo el hombre puede salvarse. La respuesta de Jünger es que la salvación está en uno mismo, convertirse en soberano de su propia persona. El lugar desde el que un individuo puede vencer es su naturaleza interior donde está la fuente donadora de sentido y valor. La única forma es resistir interiormente (Eros, amistad, arte, muerte), lugares en donde el individuo se defiende de todo ataque del Leviatán tras haber perdido el miedo66.

El propio pecho: esto es, como antiguamente en la Tebaida, el centro del mundo de los desiertos y de las ruinas (...) Aquí está cada uno, da igual de qué clase y rango, en lucha inmediata y soberana, y con su victoria se cambia el mundo. Si él es aquí más fuerte, entonces retrocederá en sí la Nada. Dejará en la orilla de la playa los tesoros que estaban sumergidos. Ellos compensarán los sacrificios ${ }^{67}$.

Jünger desconfía de la efectividad de procedimientos jurídicos formales y cree que la oportunidad de superar el nihilismo requiere de la experiencia interna en los corazones de los hombres, pues "(I)a única curación posible que aquí subsistió fue aquella que se esconde en el dolor"68. Este mero hecho de pensar desde la superación del nihilismo, o desde la línea ya cruzada (con el advenimiento del Trabajador que equivale al cruce de la línea y a una nueva donación del Ser), es lo que le confirma como un nihilista. La línea es el paso al punto cero, a la consumación de las consecuencias nihilistas aniquiladoras que tiene un momento concreto. Ernst Jünger describía dicha línea, el meridiano cero, como el punto de cumplimiento del nihilismo occidental, y con ella, la posibilidad de paso más allá, el cruce. Martin Heidegger, sin embargo, renunciaba provisionalmente al cruce,

62 lb. p. 125.

$63 \mathrm{lb}$. p. 76.

$64 \mathrm{lb}$. p. 74.

65 lb. pp. 48-49.

66 lb. p. 63.

67 lb. p. 69.

68 lb. p. 56. 
a un posible y optimista más allá, para hablar de la línea, del final y cumplimiento de la metafísica. Al movernos sobre la línea crítica se transforma el peligro porque estamos en lo no-medido donde hay menos seguridad, más posibilidad de fracaso y se exige otro ámbito del decir ${ }^{69}$. Heidegger termina por afirmar que Jünger y Nietzsche recaen en el nihilismo de un modo más fuerte. Porque la salvación supone que algo vuelve a su esencia.

En el ensayo en que le responde, Heidegger ha hecho notar que "sobre" (über) tiene dos significados, trans lineam y de lineam, correspondiendo el primero a la interpretación según la cual se ha pasado ya sobre la línea y la hemos dejado atrás, encontrándonos ahora en un más allá de la línea; mientras tanto, el segundo significado implica un detenerse y habitar la línea ${ }^{70}$. "El todo está en juego", afirman de acuerdo Jünger y Heidegger ${ }^{71}$, en la línea, en la consumación de la metafísica, en el dominio totalizado, en el nihilismo consumado, en la técnica, en definitiva ${ }^{72}$. Heidegger llamará a los intelectuales a pensar con prudencia ya que la situación planteada por Jünger es prematura intentado remontar a los fundamentos metafísicos de la cuestión. Los malentendidos sobre la metafísica provienen de una aversión al pensar porque seguimos dentro de la zona del nihilismo y el olvido del Ser. Se hace necesario un pensar meditativo para evitar esa malinterpretación ${ }^{73}$ y penetrar en la esencia del nihilismo que afecta al camino del pensar ${ }^{74}$. Para ello nos dice que hay que tener paciencia en la espera de otro inicio, en la disposición epocal de corresponder al destino del nihilismo y de la técnica: la actitud sosegada del abandono ${ }^{75}$.

El hecho de que se pase la línea traerá una nueva donación del Ser y, con ello, comenzará a resplandecer lo que es real7 ${ }^{76}$. El problema es dónde se encuentra la línea, cuándo se cruza y cuándo se supera el nihilismo. La línea está en el punto medio del nihilismo, dice Heidegger. Es decir, superando la línea no se ha cruzado, sino que se aproxima uno a sus metas $^{77}$. Heidegger propone buscar la zona de la línea crítica que localiza la esencia del nihilismo consumado ${ }^{78}$. En él, el Ser del ente no aparece porque se esconde. Heidegger

69 lb. p. 50 у p. 98.

70 lb. p. 85.

$71 \mathrm{lb}$. p. 47 у p. 76.

72 lb. p. 126.

73 lb. p. 115.

74 lb. p. 125.

75 VolPI, F. Op. cit., p. 131.

76 JÜNGER, E.; HEIDEGGER, M. Op. cit., p. 16.

77 Ib. p. 79.

78 lb. p. 112. 
dice que será la donación del Ser la que nos permita pasar la línea y que necesita de la esencia humana ya que en ésta es donde se consuma esa donación ${ }^{79}$.

\section{Algunas reflexiones finales.}

El punto central del debate epistolar publicado en Sobre la línea es la línea marcada del nihilismo que Jünger considera ya sobrepasada o a punto de ser sobrepasada por la nueva forma del Trabajador. La descripción literaria de Jünger no permite un análisis profundo del nihilismo ya que ni la voluntad de poder ni su cumplimiento en la técnica como movilización total de recursos del planeta son comprendidos en la historia del Ser ${ }^{80}$. Por el contrario Heidegger cree que el problema de la metafísica, de la voluntad de poder, tiene que ser necesariamente reconducidos a la cuestión del Ser. Bajo esta perspectiva, Jünger quedaría atrapado en el pensamiento de la inversión de valores porque ve en el nihilismo una devaluación de todos los mismos que imposibilita el contacto con un originario, limitándose por lo tanto a su descripción dentro de una literatura de síntomas, en la pérdida de los valores y de sentido, pero sin penetrar en la esencia ${ }^{81}$. Aunque bueno es destacarlo, el ensayo de Jünger identifica, por primera vez, la técnica con el proceso del nihilismo. Si la movilización total describe el proceso de apoderamiento técnico de todo lo ente a nivel planetario, el Trabajador es la figura en la cual este proceso se realiza como tarea histórica de la subjetividad moderna.

Sin embargo, para Heidegger, hay que interrogarse por la apertura epocal que hace posible la determinación del ente como voluntad de poder, un abrirse y retirarse del Ser en relación con el hombre. El Ser del ente se experimenta cada vez de modo diferente en diversas épocas (natural o artefacto, creación divina, res extensa, ciencia) como un conjunto de posibilidades determinadas de existencia donde hay un determinado desvelarse del Ser (aletheia), unas determinadas verdades compartidas y un ocultarse de todo lo que no se abre en esa revelación. Una verdad que nos viene como un destino, incontrolable, sin nuestra participación ${ }^{82}$. Este envío excluye otros modos de desvelamiento haciendo creer que la presencia epocal es total, nada del Ser falta. Pero no es así, cada época tiene sus límites ${ }^{83}$. Cuando el ente es definitivamente comprendido y determinado como

79 lb. p. 108.

80 VolPI, F. Op. cit., p. 125.

81 lb. p. 127.

82 SÁNCHEZ-MECA, D. Op. cit., p. 165.

83 lb. p. 167. 
voluntad de poder y trabajo, entonces la originaria apertura del presentarse del ente (su ser susceptible de comprensiones de ser diversas) queda bloqueada.

La confianza presente en los análisis de Jünger y en su mirada hacia el advenimiento de la técnica y de una nueva forma de poder planetario ofusca e impide, según Heidegger, un radical y profundo preguntar acerca de la esencia, que preludiaría otro comienzo en la historia del Ser. Heidegger reprocha a Jünger el hecho de ser simplemente un descriptor y no un pensador. Por esta razón Jünger puede creer, erróneamente, según Heidegger, que aquello que en realidad es el cumplimiento o la maduración epocal de la metafísica occidental sea el inicio de un tránsito a un nuevo estado de trabajo.

El olvido creciente llega a su máxima expresión en nuestra época donde el hombre se ha vuelto hacia lo evidente y practicable. Se ha estandarizado la conducta y el estilo de vida se limita a certeza y seguridad cerrándose el paso a todo lo que pudiera significar una nueva relación del Ser ${ }^{84}$. El hombre actual sólo ve necesidades concretas, se siente seguro con su técnica e indiferente a la destrucción, uniformización, programación de la cultura, facticidad de objetivos políticos, agotamiento de la naturaleza, etc. Toda la metafísica intenta decir qué significa Ser, y sin embargo, responde por el ente. En este estado, el Ser se retira de lo ente, de modo que el ente parece autosuficiente ${ }^{85}$. Esto es el olvido del Ser y es el nihilismo metafísico donde el Ser no es Nada ${ }^{86}$. La superación del nihilismo, dice Heidegger, sólo se alcanzará cuando la Nada se transforme en el Ser ${ }^{87}$.

Fin de la metafísica, nihilismo, dominio total y técnica confluyen en lo que es la línea en la que pertenecemos en nuestro tiempo. Jünger, en El Trabajador (1932) describe una realidad propia del dominio técnico total que no es otra cosa que el trabajo, el colocar al ente en la plena disposición. La duda es si la técnica inmovilizará el mundo o, por el contrario, permitirá otro comienzo de una forma que no podemos imaginar. Para Jünger en el más allá de la línea es ya la superación del nihilismo. Pero Heidegger no puede esperar su superación. No comparte la idea de trazar una línea para delimitar y sobrepasar al nihilismo como proceso de crecimiento ya que tiene que ser reducido y simplificado, porque se ha convertido en nuestra época en un estado normal ${ }^{88}$.

Posteriormente, Heidegger le achaca a éste lo mismo que le achaca a Nietzsche, la imposibilidad de una verdadera superación. Ahora bien, comprende que no sólo no se ha

84 lb. p. 173.

85 Ib. p. 184.

86 VOLPI, F. Op. cit., p. 126.

87 JÜNGER, E.; HEIDEGGER, M. Op. cit., p. 106.

88 SÁNCHEZ-MECA, D. Op. cit., p. 164. 
superado de hecho la Modernidad, sino que lo que ha acontecido fue su consumación. Heidegger señala un escollo para el intento jüngeriano de superación del nihilismo ya que se necesita una superación de la metafísica para superar el nihilismo. Este requisito hace resaltar la imposibilidad del intento de Jünger de cruzar la línea porque él pretende decir que se ha abandonado ya el nihilismo, "pero ha quedado su lenguaje"89. Es casi como si el lenguaje del nihilismo hubiera cruzado la línea y no hubiera sido alterado, cosa que Heidegger toma como prueba de que no se ha cruzado la línea en absoluto. Según Heidegger, si todo acontecer de sentido se da en el lenguaje lo es porque permite al hombre estar en medio de lo abierto del Ser, convertirse en la mediación por excelencia y condición de desvelamiento. El lenguaje abre un mundo en cuyo horizonte los entes acceden al Ser que es es quien habla y nos interpela, siendo nosotros, al oír, los elegidos ${ }^{90}$.

Si Jünger había admitido que la superación del nihilismo implicaba una nueva donación del Ser, Heidegger apunta a una alternativa que nuevamente separa las perspectivas de Jünger y la suya. Aunque aquí no lo dice explícitamente, le atribuye a Jünger la opinión de que el Ser es algo en sí mismo que accidentalmente se da a los hombres; en contra de tal interpretación, Heidegger opina que el Ser no es nada en sí mismo, sino que es la donación misma y necesita en su esencia a los hombres: el Ser se dona retirándose ${ }^{91}$. Como el Ser se disuelve en la donación, es la donación lo digno de ser preguntado. Tal es la razón por la cual en éste y en otros escritos, Heidegger escribe Ser con un cruce de tachaduras, y lo mismo la Nada. La doble tachadura no expresa simplemente una negación, sino que el Ser como donación no es nada por sí, es en la medida en que el hombre participa esencialmente de él.

\section{Coda final.}

La interpretación de la época presente y del nihilismo o, dicho en otras palabras, del acabamiento de la Modernidad y de la metafísica, tiene un lugar privilegiado en la lectura que Heidegger hace de Jünger. Ernst Jünger tiene un modo de escritura en el cual una y otra vez recurre a descripciones visuales que determinan el contenido de su doctrina ${ }^{92}$, señalando aquello sobre lo que la metafísica de Nietzsche dio luz. Este carácter visual del pensamiento de Jünger es lo que lleva a juzgarlo por Heidegger como descriptor más que como pensador.

89 JÜNGER, E.; HEIDEGGER, M. Op. cit., p. 85.

90 SÁNCHEZ-MECA, D. Op. cit., p. 169.

91 JÜNGER, E.; HeIDEGGER, M. Op. cit., p. 103 y p. 108.

92 VolPI, F. Op. cit., p. 137. 
A partir de la consumación de la metafísica y de la Modernidad, Jünger describe que el ente en su totalidad desea incrementar su voluntad de poder. Ahora bien, al atenerse a describir el ente en su totalidad, Jünger no se cuestiona por la esencia del Ser que hace posible tal descripción ni por la pregunta por la Nada, ya que queda anclado en la verdad del ente, sin poder acceder a la verdad del Ser ${ }^{93}$. Heidegger se percata inmediatamente de que esto no es más que el abandono del ente por parte del Ser, el acabamiento de la metafísica occidental, el olvido y el olvido del olvido del Ser. Heidegger vio ya a finales de los años treinta que Jünger intentó superar el nihilismo mediante un platonismo invertido que era incapaz de ver que este mismo intento es nihilista porque sigue estando sujeto al olvido del Ser, porque le hace creer que ya se ha logrado volver a una situación en la cual el Ser está presente y en la que, al menos en cierta medida, se ha dado una nueva donación del Ser.

Sin embargo, Heidegger ya no plantea un nuevo comienzo que deje atrás el nihilismo sino que, destinados como estamos a la metafísica consumada, lo que podemos hacer es llevar a cabo un pensamiento preparador que nos adentre en la esencia del nihilismo, no ya como algo negativo sino como una donación. Si alguna vez ha de llegar una nueva donación del Ser, tiene que venir del nihilismo mismo entendido ya no sólo como un fenómeno de reducción sino como un darse. Esta es la razón por la que Heidegger destaca, en referencia a Jünger, que el hombre es parte de la zona del Ser, y por lo tanto también de la Nada. El pensamiento de Heidegger, entonces, se esforzará en mantener abierta la posibilidad de otro comienzo, pero exige que se emplee un pensamiento rememorante de lo sido no pasado y que mantenga abierta la posibilidad de que la verdad del Ser no quede entumecida en una única forma que ya desembocó en el dominio planetario del nihilismo. Al igual que Nietzsche, Heidegger también oyó el mandato de meditar sobre la esencia y siguió la llamada en el camino del pensar.

\section{Referencias bibliográficas.}

CUASNICÚ, R. F. Jünger y lo político. Buenos Aires, Prometeo, 2014.

DE SÁ, A. A política sobre a linha: Martin Heidegger, Ernst Jünger e a confrontação sobre a era do niilismo. Covilhã, Luso Sofia Press, 2008.

EstradA, J.A. "La crisis axiológica y el nihilismo de Heidegger", en Pensamiento, 74, 2018, pp. 549-565.

93 JÜNGER, E.; HEIDEGGER, M. Op. cit., p. 101. 
Hervier, J. Conversaciones con Ernst Jünger. México D. F., Fondo de Cultura Económica, 1990.

HeIdegger, M. ¿Qué es metafísica? Madrid, Alianza Editorial, 2018.

JÜNGER, E. Tratado del rebelde. Buenos Aires, Sur, 1963.

JÜNGER, E. Tempestades de acero. Madrid, Fermín Uriarte, 1965.

JÜNGER, E. Eumeswil. Barcelona, Seix Barral, 1977.

JÜNGER, E. El trabajador. Dominio y figura. Barcelona, Tusquets, 1990.

JÜNGER, E. Sobre el dolor. Seguido por La movilización total. Barcelona, Tusquets, 1995.

Jünger, E.; Heidegger, M. Acerca del Nihilismo; Sobre la línea (E. Jünger); Hacia la pregunta del ser (M. Heidegger). Barcelona, Paidós, 1994.

PORCEL, D. "El lugar de la libertad en las sociedades nihilistas", en Brocar, 33, 2009, pp. 263-283.

RoldÁN, D.P. "Tecnoanthropos o el trabajador-soldado. Guerra, técnica y domesticación humana en la obra de Ernst Jünger (1920-1933)", en Revista de Filosofia, 18 (22), 2006, pp.111-146.

SÁnCHEZ-MECA, D. El nihilismo. Madrid, Síntesis, 2010.

SeVerino, E. Il destino della tecnica. Milano, Bur, 2009.

TATIÁN, D. Desde la línea. Dimensión política en Heidegger. Buenos Aires, Alción, 1997.

VoLPI, F. El nihilismo. Madrid, Siruela, 2012.

Von Krockow, C. G. La decisión. Un estudio sobre Ernst Jünger, Carl Schmitt y Martin Heidegger. Madrid, Tecnos, 2001. 